\title{
Circulating intestinal bacteria as a biological marker for colonic cancer
}

Hong Kong Med J 2020;26:353

https://doi.org/10.12809/hkmj198299

To the Editor-We are most appreciative of the communication and comments by $\mathrm{Ng}$ et $\mathrm{al}^{1}$ which draws our attention to the seminal works and landmark paper by Kwong et $\mathrm{al}^{2}$ in which no less than seven bacteria are listed to have significant association with colon cancer, with Clostridium septicum (hazard ratio $[\mathrm{HR}]=17.1$ ), Gamella morbillorum $(\mathrm{HR}=15.2)$ and Streptococcus gallolyticus or Streptococcus bovis ( $\mathrm{HR}=5.73)$ high on the list. Others have reported cancer association with even seemingly benign organisms such as Enterococcus faecalis or Escherichia coli. ${ }^{3}$ Conceivably, and with further validation, circulating intestinal bacteria may eventually become a new biomarker for colonic cancer especially at a pre-symptomatic stage. But here we need a word of caution. With an early doubling time of over 30 months, the early growth of a colorectal cancer has been shown to be slow. ${ }^{4}$ Early detection of a slow-growing cancer warrants other considerations. In our ageing population it is not too uncommon to see a patient in advanced age with multiple co-morbidities and limited life expectancy. In such cases further extensive investigations may not be justified. To complete the story of the patient with $S$ gallolyticus septicaemia we barely mentioned in an earlier communication, ${ }^{5}$ he was a 91-year-old Caucasian missionary, with advanced atherosclerotic disease, severe dementia, recurrent heart failure, deteriorating renal function, and an abdominal aneurysm for which interventional treatment was rejected. The question of colonoscopy was raised but vetoed by all parties concerned. His septicaemia was successfully controlled by penicillin and his constipation well relieved by judicious enemas instead of lactulose. He lived for another
9 months, and eventually died of heart failure. From the holistic perspective, if he had an occult colonic cancer, he probably died with it, rather than of it.

\section{Author contributions}

The author contributed to the letter, approved the final version for publication, and takes responsibility for its accuracy and integrity.

\section{Conflicts of interest}

The author has disclosed no conflict of interest.

\section{Funding/support}

This letter received no specific grant from any funding agency in the public, commercial, or not-for-profit sectors.

John SM Leung *, FCSHK, FHKAM (Surgery)

Department of Cardiothoracic Surgery, St Paul's Hospital, Causeway Bay, Hong Kong

*Corresponding author: leungsiumanjohn@yahoo.com.hk

\section{References}

1. Ng SC, Wong HK, So CK, et al. Streptococcus bovis bacteremia should be investigated for early detection of colorectal pathology. Hong Kong Med J 2019;25:414.

2. Kwong TN, Wang X, Nakatsu G, et al. Association between bacteremia from specific microbes and subsequent diagnosis of colorectal cancer. Gastroenterology 2018;155:383-90.e8.

3. Sears CL, Garrettt WS. Microbes, microbiota, and colon cancer. Cell Host Microbe 2014;15:317-28.

4. Matsui T, Yao T, Iwashita A. Natural history of early colorectal cancer. World J Surg 2000;24:1022-8.

5. Leung JSM. Streptococcal gallolyticus endocarditis-an uncommon but serious complication of constipation management. Hong Kong Med J 2019;25:257. 